\title{
谈道路地质勘察
}

\author{
马润平 \\ 内蒙古交通设计研究院有限责任公司 \\ DOI:10.18686/gmsm.v1i2.22
}

[摘 要] 随着我国经济的繁荣和公路建设事业的发展, 所涉及的地质问题越来越复杂, 工程设计对地质资料的要求也在不 断提高根据市政道路基本建设程序, 市政道路工程地质勘察与设计工作同步協调,分阶段并按各阶段要求的深度开展工作, 而谁确提供各阶段所需的地质资料,则是确保各阶段工程设计质量的前提。本文对市政道路工程地质勘察重点进行了分析, 希望能够为相关人员提供理论参考依据。

[关键词] 市政道路工程; 地质勘察; 分析

\section{1 市政道路工程地质勘察的目的}

目前, 我国市政施工单位普遍采用静力触探和钻探等技 术来进行地质勘察, 主要是对施工路线、场地进行地质勘测, 测量相应范围内的地质组成成分, 含水量, 岩层结构、稳定性 等, 得出较为精准的数据, 为之后的工程设计环节提供准确 可靠的理论依据和设计参数。还应当对测量得出结论进行分 析, 对不利于施工建设地质提出一定的建议, 保证后期的路 基设计、路面结构、压实加固等操作的正常进行。当然, 市 政道路工程的前期地质勘察有一定的测量目标, 这需要工程 前期设计路线、规划布置平面图的支持, 根据图纸以及标注 信息进行合理性勘察, 针对不同的建筑用地进行不同程度的 勘察强度, 突出工作重点, 节省工作量和勘察费用。另外, 地 质勘察有利于对建设施工地点进行定性分析, 对于是否可以 改造使用做出明智的判断, 防止出现地质塌陷、开裂等情况 而造成不必要的人力、物力损失。

\section{2 道路工程地质勘察设计的要点}

2.1 初步阶段

根据协议书的要求, 在工程可行性研究的基础上, 对道 路工程建筑场地进一步做好地质比选工作, 为初步选定工程 场地、设计方案和编制初步设计文件提供的必要工程地质依 据。第二, 首先进行综合地质勘察设计、查明路基和构造物 场地岩土层结构及工程性质, 为路基设计、选择构造物结构 和基础类型提供工程地质材料; 其次, 初步查明对工程场地 起控制作用的不良地质条件、特殊岩石类别、范围、性质、 评价对工程的危害程度, 为路线避绕或治理对策提供地质依 据; 最后, 查明场地地震烈度, 对抗震设防烈 7 度及其以上的 高烈度区进行烈度复核和地震安全性评价。

\section{2 详细阶段}

第一, 道路沿线的地质状况直接关系到路线的选择是否 合理, 以及路床和结构物是否安全稳定, 因此地质调查工作 十分重要, 否则可能会造成在施工过程中出现改线、重建或 特殊处理等问题, 这无形中加大了工程量增加了工程投资延 误了工期。地质调查必须做深、做细, 要根据道路沿线的实 际情况合理地选择地质调查方法并制定具体调查细节, 例如
需钻孔的应仔细验算钻孔间距和钻孔深度。第二, 有些高速 道路由于受线形指标等因素的制约需要贯穿耕种区域或与 排灌系统交叉时需设涵洞等构造物, 由此增加了道路建设费 用, 同时构造物过于密集也不利于机械化施工。为避免上述 问题的出现而不打乱原有排灌系统, 设计人员必须在详细调 查的基础上做出合理的综合排灌方案, 并要在取得当地政府 的书面认可后再进行结构物和改移沟渠的设计, 以避免工程 开工后进行变更设计而影响工期的情况发生。第三, 地方道 路可能会与设计主线交叉, 因此交通量预测和地方道路网规 划就显得十分重要。无论是上跨主线还是下穿主线, 都必须 按照远景要求留足跨径、宽度和净空, 避免通车后再进行改 造的损失。目前道路设计人员在进行外业调查时往往只对需 要设置互通立交的地方道路进行交通量预测, 对其它地方道 路则只调查现状而未考虑今后的发展, 这就给以后的工作增 加了难度。因此在进行此项调查时, 必须在全面了解当地的 社会、经济、道路网现状等情况的基础上, 才能对地方道路 的远景交通量进行预测以确定设计标准和等级。第四, 路基 勘探: 路基勘探应在物探工作基础上采用钻探方法查明路基 范围内溶洞分布特点、形态、规模、顶板厚度及完整性等, 在填方路段钻孔应在完整基岩内钻进 $5 \sim 8$ 米, 在该深度内 遇溶洞时, 应钻穿溶洞并在底板完整基岩内钻进 $3 \sim 5$ 米; 在 挖方路段, 钻孔应在路基设计标高以下完整基岩内钻进 $5 \sim 8$ 米, 或穿过溶洞后在底板完整基岩内钻进 $3 \sim 5$ 米。第五, 隧 道勘探: 在物探工作基础重点查明断层带、䙒皱轴部、可溶 岩与非可溶岩接触带岩溶发育情况。除洞口布设钻孔外 (钻 孔应在洞口以上 $30 \sim 50$ 米范围内), 在洞身易发育岩洞地段 布设钻孔。钻孔应在隧道底板设计标高以下完整基岩内钻进 $5 \sim 8$ 米, 在该深度内遇有溶洞时, 钻孔应穿过溶洞, 在其底板 完整基岩内钻进 $3 \sim 5$ 米。钻孔应布在中线外 7 米交叉布置。

\section{3 道路工程勘察设计中存在的问题}

3. 1 业主对施工设计的干预较多, 不利于勘察设计工作 的进行

业主在建设施工方面的管理不到位, 对于项目勘察设计 缺乏一定的约束力, 不利于勘察设计工作的顺利进行。有些 
业主在工作中过多地干预勘察设计工作, 为了加快施工进度, 随意压缩项目的勘察设计周期, 使得设计方案论证时间不足, 勘察设计工作没有达到预期的标准, 为后续的施工工作带来 隐患。对于工程项目的监管力度不严, 建设程序执行不力, 随意调整设计方案, 这些都影响了勘察设计的质量。

\section{2 勘察市场的无序和混乱}

道路建设市场不规范, 严重影响了勘察设计工作质量在 建设单位的经营过程中, 为了获得建设项目, 赢得经济利益, 经常会出现竞争压价的现象, 在勘察设计方面更是出现了分 包、挂靠等现象, 这些不规范的市场行为严重影响了勘察设 计工作的质量, 使得一些有效的资源没有办法利用, 工程勘 察设计工作实施不到位, 造成了工程浪费现象的发生, 严重 的情况还有可能引发工程事故, 为建设施工埋下安全隐患。

3.3 勘察设计单位从业人员质量控制意识淡薄

在建设单位的工作中, 一些勘察设计人员责任心不强, 对于质量控制的意识淡薄, 对于设计方案中存在缺项、漏项 等问题, 各设计阶段缺乏有效的衔接, 审核工作只流于形式; 一些勘察设计单位为了追求经济效益, 承接超出设计能力的 项目, 缺少相应的专业技术设计人员, 严重影响了勘察设计 质量。由于勘察设计人员质量和责任意识的淡薄, 出现了一 些勘察资料造假的行为, 不仅无法保证设计方案的实施, 还 给整个工程项目质量产生极坏的影响。

\section{4 道路工程勘察设计问题的措施}

4.1 根据不同地质情况提出不同的勘察要求

市政道路一般位于城市区域、为线状勘察范围, 因其地 理位置的特殊性, 导致市政道路工程地质勘察的手段、方法 与其他建筑物工程勘察有较大区别。同时由于不同的城市的 地质环境均有自己的特定条件, 要在不同的地质情况下找到 相应的勘察要求: 如在对冲积平原和山间谷地的路基勘察时, 应采用静力触探方法, 而对岗地和山区, 则应采用深挖或浅 井方法。要提高地质勘察技术, 对于不同的地质采取不同的 勘察方法, 找到相应的解决策略。同时在城市发展进程中进 行过大大小小不同程度的地质勘察, 可将其最新勘察资料和 勘察结果充分利用, 避免做重复功和无用功。如延安市区川 道地质特征明显, 在进行延安市市政道路工程地质勘察的时
候, 要在结合延安市已经累计的勘察资料和城市道路建设经 验的基础上, 酌情增减具体勘察工作量, 同时也应严肃勘察 态度, 提高勘察科学性和准确性。

\section{2 严格遵循市政道路工程地质勘察规范}

随着市政道路工程建设勘察等一系列技术的成熟, 我国 也出台了相应施工建设规范, 用于限制工程建设的随意性, 提高工程建设水平, 推动工程建设的进步。市政工程勘察工 作有一定的特殊性, 针对城市、地区的不同, 建设施工主体地 质也有所区别, 因此, 在遵守国家相关规范、标准的同时, 还 应当积极履行当地市政管理部门的相关勘察规定。另外, 道 路工程实际建设过程中, 经验是至关重要的, 勘察人员在符 合国家、地方等的规范的同时, 应该积极根据自己的工程勘 察经验, 做出有利于工程进行的判断。工程勘察规范随着运 行会有很多的变动, 这也要求工程地质勘察部门, 有效结合 新老规范要求, 尤其是岩土层方面的检测勘察, 认真分析, 有 舍有得, 积极创新, 在满足市政道路工程设计、建设的基础上, 节省勘察工作量, 推进工程的正常进行。

\section{5 结语}

综上所述, 地质勘察是市政道路设计和确保工程质量的 重要前提, 只有根据不同的地质条件, 选择不同的勘察方法, 满足不同地质的勘察要求, 严格遵循市政道路工程勘察规范, 严格按照相应标准进行勘察, 明确市政道路工程地质勘察的 目的、任务及勘察方法和手段, 加强对市政道路工程地质勘 察全过程的控制, 切实提高市政道路工程地质勘察质量, 为 市政道路的设计和施工提供更加详细的地质资料, 从而保证 市政道路施工质量。

[参考文献]

[1]王湘衡.市政道路工程地质勘察探讨 [J]. 低碳世 界,2015,(33):135-136.

[2]齐蒙, 李万里.市政道路工程地质勘察分析[J]. 工程技 术研究,2017,(11):221+227.

[3]石坤全.浅谈区域地质资料在道路勘察中的应用 [J]. 四川建筑,2018,38(03):86-87.

[4]谢超.浅析市政道路工程地质勘察过程中要注意的问 题[J].科技创新导报,2014,(01):105. 